\title{
HTLV gestacional: prevenção e cuidados de enfermagem na Atenção Primária
}

\author{
Gestational HTLV: prevention and nursing care in Primary Care
}

HTLV gestacional: prevención y atención de enfermería en Atención Primaria

\section{Resumo}

O presente estudo tem o intuito de explanar sobre o HTLV gestacional: prevenção e cuidados de enfermagem na atenção primária e apontar de modo integral, quais as principais manifestações sofridas pelas as pacientes com diagnóstico da doença. Trata-se de um estudo bibliográfico narrativo cuja trajetória metodológica apoia-se nas leituras, exploratória e seletiva do material de pesquisa bibliográfica, tendo busca bases de dados: pesquisa efetuou-se o levantamento bibliográfico nos seguintes meios eletrônicos: Scielo, LILACS, Medline, BDENF, nos meses de abril a novembro de 2021, publicações contendo informações relevantes quanto ao tema em questão. Foram utilizadas como descritores para as bases de dados internacionais as palavras: infecções por HTLV-I AND Complicações Infecciosas na Gravidez, infecções por HTLV-I AND cuidados de enfermagem, infecções por HTLV-I AND gestação. $\mathrm{O}$ critério de inclusão acerca de materiais de uso foi artigos, livros, revistas e sites que abordavam a temática. Conclui-se que os cuidados de enfermagem prestados às gestantes soropositivas ao HTLV-I além de humanizados devem ser pautados na orientação para a não amamentação, ficando claro para a gestante o risco que reside na transmissão do vírus bem como na possibilidade do surgimento de outros processos patológicos. Por conseguinte se faz necessário fortalecer a importância do preparo da equipe de enfermagem, no acolhimento e cuidados a gestante soropositivo, bem como expandir os achados sobre tal problemática por meio de educação em saúde e orientações, para que a coletividade se aproprie de conhecimento suficiente com foco em promover ações de prevenção ao vírus e redução de possíveis agravos.

Palavras-chave: Infecções; HTLV; Gestação; Cuidados de enfermagem. 


\begin{abstract}
The present study aims to explain about gestational HTLV: prevention and nursing care in primary attention and to point out in full what the main manifestations suffered by patients with diagnosis of the disease are. This is a narrative bibliographic study whose methodological trajectory is based on the readings, exploratory and selective exploration of bibliographic research material, searching for databases: the bibliographic survey was carried out in the following electronic media: Scielo, LILACS, Medline, BDENF, in the months of April to November of 2021, publications containing relevant information on the subject in question. Words were used as descriptors for international databases: HTLV-I infections and Infectious Pregnancy Complications, HTLV-I infections and nursing care, HTLV-I and gestation infections. The inclusion criterion for materials for use was articles, books, magazines and websites that addressed the topic. It is concluded that nursing care provided to HIV-positive pregnants and to HTLV-I should be guided in the direction of non-breast-feeding, making it clear to the pregnant person the risk of transmission of the virus and the possibility of other pathological processes arising. It is therefore necessary to strengthen the importance of the preparation of the nursing team, in the reception and treatment of HIV-positive pregnant women, as well as to expand the findings on such problems through health education and guidance, so that the collective appropriates sufficient knowledge with a focus on promoting actions to prevent the virus and reducing possible staples.
\end{abstract}

Keywords: Infections; HTLV; Pregnancy; Nursing care.

\title{
Resumen
}

El objetivo de este estudio fue explicar el HTLV durante el embarazo: la principal preocupación en la prevención y enfermería, y señalar de manera integral las principales manifestaciones de los pacientes diagnosticados con HTLV. Se trata de un estudio bibliográfico descriptivo, cuya trayectoria metodológica se basa en la lectura, exploración exploratoria y selectiva de materiales bibliográficos, búsqueda de bases de datos: la encuesta bibliográfica se llevó a cabo en los siguientes medios electrónicos entre abril y noviembre de 2021: Scielo, LILLACS, Medline, BDENF, Una publicación que contiene información sobre un tema. Estos términos se utilizan como descriptores de bases de datos internacionales: infección por HTLV-I y complicaciones infecciosas del embarazo, infección por HTLV-I y cuidados de enfermería, infección por HTLV-I e infección por embarazo. Los criterios de inclusión para el uso de materiales son los artículos, libros, revistas y sitios web sobre el tema. La conclusión es que la atención prestada a las mujeres embarazadas seropositivas y al HTLV-I debe seguir la dirección de la no lactancia materna para identificar a las mujeres embarazadas el riesgo de transmisión del virus y otros posibles procesos patológicos. Por consiguiente, es necesario mejorar la preparación de los equipos de enfermería para recibir y tratar a las mujeres embarazadas seropositivas y ampliar las conclusiones sobre estas cuestiones mediante la educación y la orientación en materia de salud. De esta manera, el Grupo tiene conocimientos suficientes, haciendo hincapié en la promoción de medidas de prevención del virus y la reducción de los posibles alimentos básicos.

Palabra clave: Infección; HTLV; Embarazo; Cuidado.

\section{Introdução}

O HTLV-I foi descoberto pelo cientista americano Dr. Robert C. Gallo na década de 1980, tornando-o então o único pesquisador a expor o retrovírus humano do mundo. Em 1982, ele registrou o segundo retrovírus humano, HTLV-II, e durante mais pesquisas, descobriu o HTLV-III, que foi denominado como HIV, o vírus que ocasiona a AIDS (Santos 2017).

O vírus linfotrópico de células T humana (HTLV) é um vírus que atinge os linfócitos T que são células defensoras do corpo humano e com a destruição das mesmas causam diversos danos à saúde, o HTLV-I e II fora descoberto há 40 anos, são correlacionados, porém distintos um do outro, sendo que o HTLV-II é menos patogênico, podendo haver o aparecimento ou não da doença, e tornando esse portador como assintomático (Catalan, 2001).

Segundo Araújo (2018), o HTLV é um vírus que pode ocasionar diversas doenças tais como: HAM/TSP- Mielopatia associada ao HTLV-1/paraparesia espástica tropical, do qual pode acarretar em astenia e paralisia dos membros inferiores e também pode ocasionar a (LLTA) Leucemia /Linfoma de células T no adulto.

O HTLV é um problema de saúde pública, caso não seja diagnosticada e tratada precocemente podem levar os portadores da doença a se tornarem cadeirantes ou ate mesmo evoluir a óbito. No Brasil não há uma forma de investigação pontual sobre o vírus por este não fazer parte da lista de IST’S (infecções sexualmente transmissíveis) bem como a de agravos de notificação compulsória, a outra problemática em questão reside no fato de a sorologia para gestantes não fazer parte dos exames obrigatórios no pré-natal (Garcia \& E Hennington, 2019). 
Segundo Romanelli (2010), "Estima-se que o Brasil tenha cerca de 2,5 milhões de portadores do vírus, o que representa o maior número absoluto de infecções no mundo". Entretanto, as taxas de prevalência são bastante heterogêneas, e essa variação depende tanto da região geográfica, como dos grupos analisados: Jovens, gestantes, mulheres dentre outros.

Segundo Sales (2017), a transmissão é feita através da via vertical e horizontal, por meio da amamentação, sexo desprotegido, compartilhamento de seringas, agulhas contaminadas e transfusão sanguínea.

A transmissão do HTLV gestacional se dar de forma vertical, sendo que a não amamentação e a triagem sorológica é uma forma de evitar a transmissibilidade do vírus e surgimento de doenças relacionadas a ele, por isso é de extrema importância às orientações correta a essa gestante soropositiva ao HTLV (Figueredo, 2019).

A transmissibilidade de doenças pode ocorrer durante ou após o trabalho de parto, podendo ser através do leite materno, desencadeando um alerta uma vez que pode ocasionar risco de mortalidade tanto para a mãe quanto para a criança (Botelho, 2008).

Na presença da soropositividade gestacional para o vírus HTLV-I, a orientação a ser feita é a não amamentação, com a substituição do leite materno pelo leite artificial industrializado, tornando-se necessário que o profissional de saúde enfermeiro oriente sobre as alternativas de alimentação para criança, evitando assim o risco de contaminação da mãe para o bebê (Sales, 2017).

Sabe-se que a amamentação exclusiva até os seis meses é fundamental para a vida do bebê, pois o leite materno oferece anticorpos, nutrientes e minerais, e que todos corroboram para um crescimento saudável. Todavia, a gestante que possuir o diagnóstico de HTLV-I deve ser orientada a não realizar a amamentação uma vez que o vírus pode ofertar riscos à saúde da criança (Figueredo, 2019).

A maioria das pessoas que possuem o vírus não apresentam sintomatologia, e somente $10 \%$ dos infectados manifestarão alguns sinais e sintomas e consequentemente o surgimento de doenças associadas a ele, como por exemplo: doenças neurológicas, oftalmológicas, dermatológicas, urológicas e hematológicas, sendo a hematológica a leucemia/linfoma associada ao HTLV (Catalan, 2001).

A leucemia/linfoma de células T do adulto (ATL) é considerada agressiva linfoproliferativa, onde os linfócitos se proliferam em quantidades excessivas, esse tipo de leucemia é causado pelo vírus HTLV e possui uma imensa dificuldade em responder a quimioterapia, tornando-se assim fatal ao portador da doença (Bittencourt et al, 2008).

Paraparesia espástica tropical/mielopatia associada ao HTLV-I (PET/MAH), doença que acomete mais mulheres e jovens, ocasiona um processo inflamatório medular que gera astenia muscular e espasticidade nos membros inferiores (MMII), ocasionando complicações na marcha e em diversos casos leva os pacientes a fazerem o obrigatório de cadeira de rodas (Lannes, 2006).

A sorologia do HTLV deveria ser obrigatória durante a consulta de pré-natal, pois o Brasil está à frente de todos os demais países da América Latina, liderando com o maior número de pessoas contaminadas pelo HTLV-I, se existisse uma obrigatoriedade seria possível pensar sobre uma redução no numero de casos e ventilar a ideia de política publica voltada para a erradicação do mesmo (Brasil, 2018).

Segundo Bittencourt (2008) um dos métodos utilizados para a descoberta de anticorpos anti HTLV-I no soro é o imunoenzimático (Elisa) que deve ser confirmado pelo Western-blot, que permite a diferenciação entre os tipos I e II do HTLV. Em casos onde não é possível confirmar a infecção através dessa técnica, deverá ser utilizada a reação em cadeia da polimerase que detecta o DNA retroviral, dessa maneira é descoberto se há quadro de infecção no corpo humano.

Para que haja eficácia e qualidade no atendimento da enfermagem a essas gestantes, é fundamental que se tenham conhecimento sobre a SAE (Sistematização da Assistência de Enfermagem) de maneira abrangente e correta, iniciando sempre 
com anamnese investigatória e, estando sempre atenta a todo histórico relatado, dessa maneira o atendimento se tornará diversificado durante o acolhimento, evitando assim possíveis riscos à mãe e ao bebê. (Resolução Cofen 358/2009).

Deve ser realizado o processo de enfermagem de acordo com a SAE, pois é um método científico que presta assistência ampla e geral, que traz na sua prática segurança aos pacientes, atendimento diferenciado, humanizado, atendendo a todos de maneira integral e igualitária, cabendo assim uma maior autonomia aos profissionais de enfermagem (Tannure \& Pinheiro, 2014).

O histórico de enfermagem é imprescindível para uma tomada de decisão acerca dos achados obtidos do paciente. Fornecendo a base para a elaboração de diagnóstico e intervenções buscando alçar resultados positivos pelos quais o enfermeiro é responsável. (Resolução Cofen 358/2009).

Portanto, o presente estudo tem o intuito de explanar sobre o Htlv gestacional: prevenção e cuidados de enfermagem na atenção primária e apontar de modo integral, quais as principais manifestações sofridas pelas as pacientes com diagnóstico da doença.

O artigo encontra-se estruturado em sessões, que contemplam a introdução onde é tratada sobre o Htlv gestacional: prevenção e cuidados de enfermagem na atenção primária, em sua conjuntura total, as sessões seguintes tratarão a metodologia utilizada para a elaboração do artigo e os resultados e discussões como produto de todo o conteúdo escrito, por fim as considerações finais, finalizando a ideia central e sancionando os pontos de maior significância constatada no decorrer desta produção.

\section{Metodologia}

Para alcançar os objetivos da pesquisa efetuou-se o levantamento bibliográfico nos seguintes meios eletrônicos: Scielo, LILACS, Medline, BDENF, nos meses de abril a novembro de 2021, publicações contendo informações relevantes quanto ao tema em questão. Foram utilizadas como descritores para as bases de dados internacionais as palavras: infecções por HTLV-I AND Complicações Infecciosas na Gravidez, infecções por HTLV-I AND cuidados de enfermagem, infecções por HTLV-I AND gestação. O critério de inclusão acerca de materiais de uso foi artigos, livros, revistas e sites que abordavam a temática.

Foram encontrados no total de 5.602 artigos, após exclusão de repetição e aplicação pós-filtro ficaram 4.120 artigos, pós-exclusão de análise, leitura de título e resumos repetidos restaram 24 e artigos incluídos no texto foram 18. 
Figura 1. Fluxograma de busca nas bases de dados para revisão integrativa sobre cuidados de enfermagem às pacientes gestantes com HTLV.
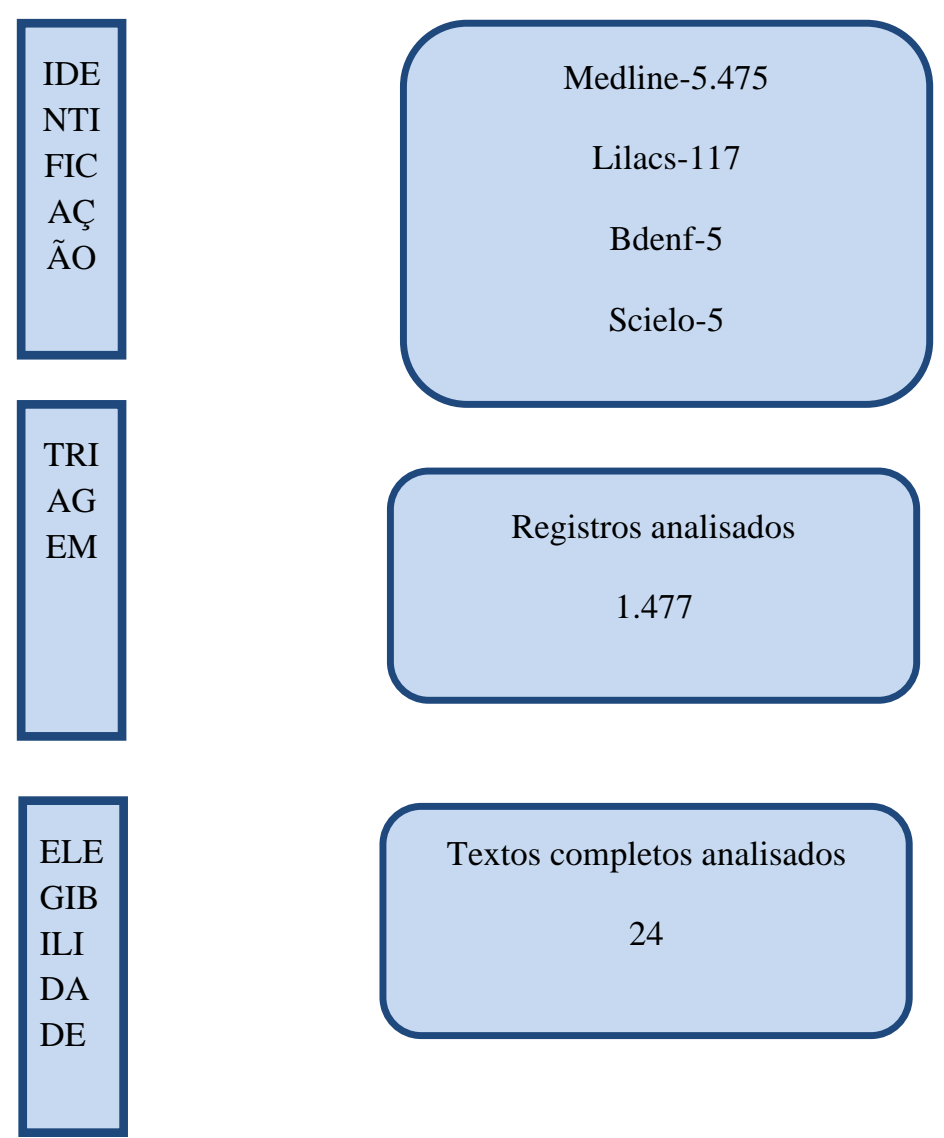

Textos completos analisados

24

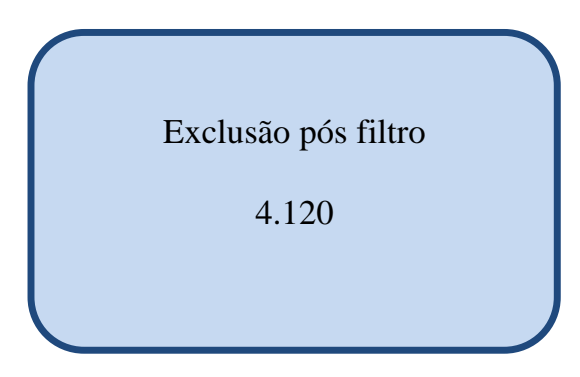

Exclusão após leitura do título, resumo e repetição.

1456

Exclusão após leitura do texto completo

18
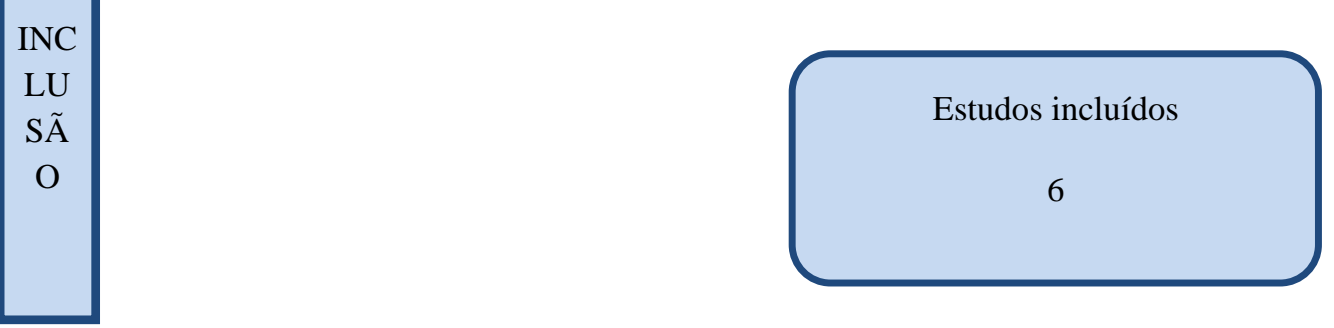

Fonte: Autores.

Na Figura 1, é indicado o processo de identificação e seleção dos estudos de acordo com as recomendações do Preferred Reporting Items for Systematic Reviews and MetaAnalyses (PRISMA).

\section{Resultados e Discussões}

Quadro 1. Artigos selecionados.

\begin{tabular}{|c|c|c|c|c|c|}
\hline $\mathbf{N}^{\circ}$ & Autor & Ano & Título & Objetivos & Resultados \\
\hline 1 & Sales, et al. & 2017 & $\begin{array}{c}\text { Vírus T- Linfotrópicos } \\
\text { humanos em gestantes e } \\
\text { suas nuances. Saberes de } \\
\text { enfermeiro. }\end{array}$ & $\begin{array}{l}\text { Analisar os saberes de enfermeiros } \\
\text { atuantes nos serviços - Centro de } \\
\text { Testagem e Aconselhamento/Serviço de } \\
\text { Atendimento Especializado (CTA/SAE) } \\
\text { e Unidades de Saúde da Família (USF) } \\
\text { no que concerne sobre HTLV em } \\
\text { gestantes. }\end{array}$ & $\begin{array}{l}\text { O vírus silencioso e os saberes sobre a } \\
\text { doença e quando a soropositividade atinge } \\
\text { as gestantes. Reconhece-se que os } \\
\text { enfermeiros são pouco instruídos durante a } \\
\text { graduação quanto à temática. }\end{array}$ \\
\hline
\end{tabular}




\begin{tabular}{|c|c|c|c|c|c|}
\hline 2 & Dias, E.A. & 2019 & $\begin{array}{c}\text { Sistematização da } \\
\text { assistência de enfermagem } \\
\text { ao paciente com HTLV: } \\
\text { Proposta de elaboração de } \\
\text { instrumento para a } \\
\text { assistência. }\end{array}$ & $\begin{array}{l}\text { Para que se tenha uma assistência de } \\
\text { enfermagem adequada e individualizada } \\
\text { é necessária a aplicação de uma } \\
\text { Sistematização da Assistência de } \\
\text { Enfermagem. }\end{array}$ & $\begin{array}{l}\text { O estudo permitiu uma reflexão quanto às } \\
\text { características comuns aos pacientes } \\
\text { sintomáticos para o HTLV, que geraram a } \\
\text { construção da ficha clínica de avaliação } \\
\text { desse público proposta nesta investigação, } \\
\text { o que auxiliará o profissional de } \\
\text { enfermagem envolvido no atendimento. }\end{array}$ \\
\hline 3 & SILVA, et al. & 2016 & $\begin{array}{l}\text { Atuação da enfermeira no } \\
\text { cuidado a gestante } \\
\text { infectada pelo HLTV-1 e } \\
2 .\end{array}$ & $\begin{array}{l}\text { Esse estudo tem como objetivo geral } \\
\text { descrever a atuação da enfermeira no } \\
\text { cuidado a gestante infectada pelo } \\
\text { HTLV-1 e } 2 \text { e específico, identificar } \\
\text { complicações em mulheres gestantes } \\
\text { infectadas pelo HTLV-1 e } 2 \text {. }\end{array}$ & $\begin{array}{l}\text { A enfermeira junto com a equipe } \\
\text { multiprofissional exerce papel importante } \\
\text { na assistência pré-natal, parto e puerpério, } \\
\text { seja na detecção precoce da infecção pelo } \\
\text { HTLV-1 e 2, triagem dessa população } \\
\text { vulnerável e familiares para orientações e } \\
\text { encaminhamentos a rede assistencial, } \\
\text { impactando desse modo nos elevados } \\
\text { níveis de transmissão vertical. }\end{array}$ \\
\hline 4 & $\begin{array}{c}\text { DA } \\
\text { SILVA, et al. }\end{array}$ & 2017 & $\begin{array}{l}\text { Vírus HTLV e educação } \\
\text { em saúde: construção de } \\
\text { uma cartilha educativa } \\
\text { como estratégia de } \\
\text { prevenção utilizada pelo } \\
\text { enfermeiro. }\end{array}$ & $\begin{array}{l}\text { Elaborar uma cartilha educativa sobre o } \\
\text { HTLV para utilização com adolescentes. }\end{array}$ & $\begin{array}{l}\text { Espera-se que com base nos nossos } \\
\text { estudos, o conteúdo didático presente na } \\
\text { cartilha forneça informações de grande } \\
\text { importância para a população geral. }\end{array}$ \\
\hline 5 & $\begin{array}{l}\text { DE } \\
\text { OLIVEIRA. } \\
\text { et al. }\end{array}$ & 2017 & $\begin{array}{l}\text { Infecção pelo Vírus T- } \\
\text { linfotrópico Humano } \\
\text { (HTLV): Relato de Caso } \\
\text { Baseado no Processo de } \\
\text { Enfermagem. }\end{array}$ & $\begin{array}{l}\text { Modelos e impactos do cuidado de } \\
\text { enfermagem nas condições de saúde da } \\
\text { população }\end{array}$ & $\begin{array}{l}\text { Busca mostrar o desenvolvimento e } \\
\text { avaliação de políticas e modelos de } \\
\text { cuidado de enfermagem em serviços de } \\
\text { atenção hospitalar. }\end{array}$ \\
\hline 6 & $\begin{array}{l}\text { SOUZA. et } \\
\text { al. }\end{array}$ & 2020 & $\begin{array}{l}\text { Diagnósticos de } \\
\text { enfermagem em pessoas } \\
\text { soropositivas pelo vírus } \\
\text { linfotrópico T humano. }\end{array}$ & $\begin{array}{l}\text { Identificar diagnósticos de enfermagem } \\
\text { em pessoas sintomáticas e soropositivas } \\
\text { para o vírus linfotrópico T humano. }\end{array}$ & $\begin{array}{l}\text { A apresentação e análise dos diagnósticos } \\
\text { de enfermagem foram listadas por } \\
\text { domínios, favorecendo a identificação das } \\
\text { áreas de conhecimentos essenciais para a } \\
\text { realização do cuidar das pessoas } \\
\text { soropositivas para HTLV I/II sintomáticas. }\end{array}$ \\
\hline
\end{tabular}

Fonte: Revisão de literatura elaborada pelos autores (2021).

Para que haja um diagnóstico concreto do vírus HTLV, é necessária que o enfermeiro ao iniciar o pré-natal inclua nos exames a sorologia através do teste denominado ELISA (imunoensaio enzimático), teste de aglutinação para observar se há anticorpos contra o vírus, para teste de confirmação é utilizado o Western Blot, que verifica a infecção do vírus e o tipo se é HTLV I ou HTLV-II (Romanelli, 2010).

A enfermagem na atenção primária fará um acompanhamento de pré-natal à gestante com HTLV-I, dessa maneira pode reduzir os riscos de transmissibilidade ao bebê, essa gestante será considera como de alto risco, terá atendimento por uma equipe multidisciplinar, composta prioritariamente por médico, psicóloga dentre outros profissionais, a mesma estará amparada durante todo o pré-natal e puerpério. No puerpério é acompanhada pela equipe para orientação a não amamentação prevenindo o risco de transmissão do vírus ao bebê. Fazendo o enquadramento da mãe em programas de estratégia de saúde da família, que ofertará leite as mães não aptas à amamentação (Sales, 2017).

Os cuidados de enfermagem buscam oferecer assistência integral, promoção e prevenção às gestantes portadoras do HTLV, o profissional de enfermagem que estiver em atendimento na atenção primária deve estar atento e capacitado para atender as necessidades da paciente com HTLV, observar sinais, sintomas apresentados ou aqueles que poderão surgir ofertando apoio emocional (Silva, 2016).

O processo da sistematização da assistência é promovido pela equipe de enfermagem ás gestante soropositiva ao HTLV será planejado e ordenado objetivando a criação e fortalecimento de vinculo entre profissional e a paciente o que permitirá melhor orientação quanto à doença e melhor enquadramento da gestante na sociedade ainda que essa pouco conheça sobre o desenvolvimento da patologia (Dias, 2019).

A equipe deverá orientar a gestante soropositiva a não amamentar seu filho, e a não permitir que outras mães o amamentem sem o devido acompanhamento e orientação, pois além do HTLV outras doenças podem ser transmitidas via leite 
materno, nesses casos o bebê receberá fórmula infantil até seis meses e após ocorrera a oferta de outros alimentos para a sua nutrição, prevenindo, portanto a transmissão vertical (Sales 2017).

\section{Considerações Finais}

A triagem sorológica para detecção do HTLV-I deve se tornar prioridade na atenção básica, uma vez que os cuidados prestados pela equipe de enfermagem às gestantes soropositivas ocorreriam de maneira diferenciada, tornando as mães prioridade em atendimento, focando no processo de promoção a saúde objetivando melhora na qualidade de vida mesmo diante da problemática.

Os cuidados de enfermagem prestados às gestantes soropositivas ao HTLV-I além de humanizados devem ser pautados na orientação para a não amamentação, ficando claro para a gestante o risco que reside na transmissão do vírus bem como na possibilidade do surgimento de outros processos patológicos.

Portanto um pré-natal de qualidade pode evitar complicações futuras à mãe e ao bebê, reduzindo a possibilidade de problemas psicossociais, depressão, ansiedade, medo e até mesmo sentimento de culpa que pode cometer essa mulher, dessa maneira as gestantes se sentirão amparadas e seguras quanto ao seu desenvolvimento gestacional, parto e puerpério.

Por conseguinte se faz necessário fortalecer a importância do preparo da equipe de enfermagem, no acolhimento e cuidados a gestante soropositivo, bem como expandir os achados sobre tal problemática por meio de educação em saúde e orientações, para que a coletividade se aproprie de conhecimento suficiente com foco em promover ações de prevenção ao vírus e redução de possíveis agravos.

Sucintamente, para trabalhos futuros sugere-se que seja realizado um estudo de campo abordando a importância do Htlv gestacional: prevenção e cuidados de enfermagem na atenção primária.

\section{Referências}

Araújo, C. A. (2018). Dia Mundial do HTLV-10 de Novembro. Revista do Instituto Adolfo Lutz, 77, 1-4.

Bandeira, L. M., Puga, M. A. M., \& Motta-Castro, A. R. C. (2021). Infecção pelo HTLV: uma visão geral.

Bittencourt, A. L.; \& Farré L. (2008). Leucemia/linfoma de células T do adulto. Anais brasileiro de dermatologia. (4), 83.

Botelho, C. A. O. (2008). Prevalência dos agravos triados no programa de proteção à gestante do estado de Mato Grosso do Sul de 2004 a 2007 . Epub.

Carneiro. P. A. B. F. et al. (2002). Infecção e doença pelos vírus linfotrópicos humanos de células T (HTLV-I/II) no Brasil. Revista da Sociedade Brasileira de Medicina Tropical, 35, 499-508.

Catalan, B. C. S. et al. (2001). Os vírus linfotrópicos de células T humanos (HTLV) na última década (1990-2000): Aspectos epidemiológicos. Revista Brasileira de Epidemiologia, 4, 81-95.

Da Silva, J. D. A. A. et al. (2017). Vírus HTLV e educação em saúde: construção de uma cartilha educativa como estratégia de prevenção utilizada pelo enfermeiro. Revista Rede de Cuidados em Saúde, 10(1).

De Enfermagem, Conselho Federal. Resolução COFEN-358/2009. (2009) Dispõe sobre a sistematização da assistência de enfermagem-SAE nas instituições de saúde brasileiras [legislação na Internet]. Brasília, 2009.

De Oliveira, P. J. F. et al. Infecção pelo Vírus T-linfotrópico Humano (HTLV): Relato de Caso Baseado no Processo de Enfermagem. (2017). In: Congresso Internacional de Enfermagem, 1(1).

Dias, E. D. A. (2019). Sistematização da Assistência de Enfermagem ao paciente com HTLV: proposta de elaboração de instrumento para a assistência.

Figueiredo-Alves, R. R., Nonato, D. R., \& Cunha, A. M. (2019). HTLV e gravidez: protocolo clínico. Femina, $110-113$.

Garcia, I. F. D. S., \& Hennington, É. A. (2019). HTLV: uma infecção estigmatizante? Cadernos de Saúde Pública, 35.

Lannes, P., Neves, M. A. O., Machado, D. D. C. D., Miana, L. C., Silva, J. G., \& do Vale Bastos, V. H. (2006). Paraparesia Espástica Tropical-Mielopatia associada ao vírus HTLV-I:: possíveis estratégias cinesioterapêuticas para a melhora dos padrões de marcha em portadores sintomáticos. Revista Neurociências, 14(3), 153-160.

Proietti, A. B. F. C. (2015). Cadernos Hemominas: Cadernos Hemominas. 
Research, Society and Development, v. 10, n. 16, e151101623754, 2021

(CC BY 4.0) | ISSN 2525-3409 | DOI: http://dx.doi.org/10.33448/rsd-v10i16.23754

Romanelli, L. C. F., Caramelli, P., \& Proietti, A. B. D. F. C. (2010). O vírus linfotrópico de células T humanos tipo 1 (HTLV-1): Quando suspeitar da infecção? Revista da Associação Médica Brasileira, 56, 340-347.

Rosadas, C., Brites, C., Arakaki-Sánchez, D., Casseb, J., \& Ishak, R. (2021). Protocolo Brasileiro para Infecções Sexualmente Transmissíveis 2020: infecção pelo vírus linfotrópico de células T humanas (HTLV). Epidemiologia e Serviços de Saúde, 30.

Sales, J. R. P. D., Melo, M. C. P. D., Mistura, C., Silva Filho, C. C., Silva, L. S., \& Cruz, D. D. (2017). Vírus t-linfotrópicos humanos em gestantes e suas nuances: saberes de enfermeiros. Rev. enferm. UFPE on line, 2856-2863.

Santos, A. C. C. D., Soares, D. D. J., \& Rivemales, M. D. C. C. (2017). (Des) conhecimento, adoecimento e limitações impostas pelo HTLV: experiências de mulheres soropositivas. Cadernos Saúde Coletiva, 25, 45-50.

Silva, C. A. C. D., Garcia, C. P. D. C., \& Silva, A. N. D. (2016). Atuação da enfermeira no cuidado a gestante infectada pelo HLTV-1 e 2.

Souza, L. S., Sampaio, D. C., Rivemales, M. D. C. C., Oliveira, L. L. C., de Jesus, A. P. S., da Maia Lima, C. F., \& de Carvalho Félix, N. D. (2020). Diagnósticos de enfermagem em pessoas soropositivas pelo vírus linfotrópico t humano. Revista Baiana de Enfermagem34 ,.

Tannure, M. C., \& Pinheiro, A. M. (2011). SAE: Sistematização da Assistência de Enfermagem: guia prático. In SAE: sistematização da assistência de enfermagem: guia prático (pp. 298-298). 